\title{
scratch, a pan-neural gene encoding a zinc finger protein related to snail, promotes neuronal development
}

\author{
Margaret Roark, ${ }^{1,2}$ Mark A. Sturtevant, ${ }^{2}$ John Emery, ${ }^{2}$ Harald Vaessin, ${ }^{3,4}$ Ellsworth Grell, ${ }^{3}$ \\ and Ethan Bier ${ }^{2,5}$ \\ ${ }^{1}$ Biological Sciences Program, California State University, San Marcos, California 92096 USA; ${ }^{2}$ Department of Biology and \\ Center for Molecular Genetics, University of California, San Diego, La Jolla, California 92093 USA; ${ }^{3}$ Howard Hughes \\ Medical Institute, University of California, San Francisco, California 94143AUSA; ${ }^{4}$ Neurobiotechnology Center and \\ Department of Molecular Genetics, Ohio State University, Columbus, Ohio 43210-1002 USA
}

The Drosophila scratch (scrt) gene is expressed in most or all neuronal precursor cells and encodes a predicted zinc finger transcription factor closely related to the product of the mesoderm determination gene snail (sna). Adult flies homozygous for scrt null alleles have a reduced number of photoreceptors in the eye, and embryos lacking the function of both scrt and the pan-neural gene deadpan (dpn), which encodes a basic helix-loop-helix (bHLH) protein, exhibit a significant loss of neurons. Conversely, ectopic expression of a scrt transgene during embryonic and adult development leads to the production of supernumerary neurons. Consistent with scrt functioning as a transcription factor, various genes are more broadly expressed than normal in scrt null mutants. Reciprocally, these same genes are expressed at reduced levels in response to ectopic scrt expression. We propose that scrt promotes neuronal cell fates by suppressing expression of genes promoting non-neuronal cell fates. We discuss the similarities between the roles of the ancestrally related scrt, sna, and escargot $(e s c)$ genes in regulating cell fate choices.

[Key Words: scrt; sna; pan-neural; Drosophila; transcription factor; zinc finger; neurogenesis]

Received May 26, 1995; revised version accepted August 9, 1995.

Cells giving rise to basic tissue types derive from three different primary dorsal-ventral regions of the early Drosophila blastoderm embryo. Ventral cells invaginate during early gastrulation to generate the mesoderm, cells from the ventral portion of a broad lateral domain / the neuroectoderm) are progenitors of the central nervous system (CNS) and ventral epidermis, and cells from the dorsal portion of the lateral domain as well as the ventral portion of the dorsal domain give rise to the peripheral nervous system (PNS) and epidermis. Mesoderm formation depends on the action of two ventrally expressed genes: twist (twi), which encodes a basic helix-loop-helix (bHLH) type of transcription factor (Thisse et al. 1988), and snail (sna), which encodes a transcription factor with five zinc fingers (Boulay et al. 1987). twi functions primarily by activating expression of mesodermspecific target genes, whereas sna functions to repress expression of nonmesodermal genes such as the neuroectodermal achaete-scute complex (AS-C) genes, rhomboid (rho), and short gastrulation (Kosman et al. 1991; Leptin et al. 1991; Rao et al. 1991; Ip et al. 1992; François et al. 1994).

Regional activation of genes is also believed to con-

${ }^{5}$ Corresponding author. tribute to the production of a highly stereotyped pattern of primary neuronal precursor cells in the CNS (neuroblasts) and in the PNS [sensory mother cells (SMCs)]. For example, neuroectodermal expression of AS-C genes (Romani et al. 1987, 1989), which encode a family of related bHLH transcription factors/Villares and Cabrera 1987; Alonso and Cabrera 1988), provides a necessary precondition for neuronal development. A lateral inhibitory process restricts the number of cells within these zones of neuronal competence differentiating as primary neuronal precursor cells (for review, see Artavanis-Tsakonis and Simpson 1991; Ghysen et al. 1993; Jan and Jan 1993; Campos-Ortega 1994).

Once neuronal precursor cells are selected, a group of genes referred to as pan-neural genes begin to be expressed in most or all of these cells in both the CNS and PNS. One pan-neural gene, deadpan (dpn), encodes a bHLH protein closely related to the product of the hairy gene (Bier et al. 1992). While $d p n$ is essential for viability, the nervous system appears morphologically normal in embryos homozygous for $d p n-$ null alleles (Bier et al. 1992). Thus, it is likely that other genes collaborate with $d p n$ to control neuronal development.

In this paper we describe the cloning of the pan-neural gene, scratch (scrt). scrt encodes a zinc finger type of 
transcription factor closely related to the product of the mesoderm determination gene sna. Elimination of scrt function results in a mild reduction of photoreceptor cell number in escaping adult flies but does not obviously disrupt morphogenesis of the embryonic nervous system. However, double mutant embryos lacking both scrt and $d p n$ display a significant loss of neurons. This neuronal loss phenotype is evident early during neurogenesis as the number of neuroblasts is reduced in $s c r t ; d p n$ double mutant embryos. Conversely, ubiquitous expression of scrt in transformed flies carrying scrt under the control of a heat shock promoter (HS-scrt flies) leads to the production of extra neurons during embryogenesis and adult neurogenesis. The increased number of neurons in HS-scrt embryos may be attributable in part to the precocious appearance of neuronal precursor cells. Finally, we provide evidence that scrt functions to repress expression of various target genes including the non-neuronal Drosophila Egf-Receptor (Egf-r) gene. These data suggest that scrt functions in combination with $d p n$ to promote neuronal differentiation by repressing expression of genes promoting non-neuronal fates. We compare the roles of scrt and $d p n$ in neurogenesis to that of sna in mesoderm formation.

\section{Results}

Identification of scrt, a new gene expressed in all neuronal precursors

Several enhancer trap lines recovered in a screen for patterned gene expression (Bier et al. 1989) express lacZ in a pan-neural pattern (Bier et al. 1992). Among these panneural insertions, two map cytologically to the $64 \mathrm{~A}$ region of the third chromosome. Genomic DNA flanking one of the P-element insertion sites was isolated by plasmid rescue. An antisense digoxigenin-labeled RNA probe made from one of the rescued genomic fragments hybridized in situ to a transcript expressed in the predicted pan-neural pattern (Fig. 1; see Materials and methods for details of cloning). We have named this flanking gene scrt on the basis of one of the phenotypes exhibited by survivors homozygous for a deletion of the coding sequences (scarred facets in the eye) and on the presence of five zinc-finger domains (Fig. 3B) in the encoded protein (see below). scrt transcripts are first detectable in a single row of ectodermal cells flanking the ventral midline (Fig. 1A) during the early germ-bandextended stage (stage 8). scrt-expressing cells then delaminate and contribute to the first of three rows (r1-r3) of $\mathrm{S} 1$ neuroblasts in the CNS (Fig. 1B,C). scrt is subsequently expressed in all S1 neuroblasts as well as in neuroblasts formed during later rounds of segregation. scrt continues to be expressed throughout the neuronal lineage in cells likely to be the immediate progeny of neuroblasts, the ganglion mother cells (GMCs), and then in postmitotic neurons. scrt expression differs from that of $d p n$ in that $d p n$ is not expressed in GMCs (Bier et al. 1992). This is illustrated in Figure 1D, where scrt expression in GMCs obscures the rosette pattern of neuroblasts expressing $d p n$ in a late germ-band-extended embryo (Fig. IE). Similarly, in the PNS scrt is first expressed in primary SMCs (Fig. 1D), then in cells likely to be secondary precursor cells (Fig. 1F), and finally in postmitotic neurons (Fig. 1G). Neuronal expression of $l a c Z$ derived from scrt enhancer trap insertions persists long enough to label all identified neurons of the PNS (Fig. 1G,H).

We have used double label in situ hybridization (O'Neill and Bier 1994) to compare the pattern of scrt expression to that of $d p n$ and sna. This analysis reveals that in the embryo most or all cells of the nervous system expressing scrt also express $d p n$ (data not shown), consistent with the view that these two genes are expressed in most or all primary neuronal precursor cells. The onset of scrt and $d p n$ expression appears to vary among neuroblasts. $s c r t$ is expressed before $d p n$ in the first row of neuroblasts. Subsequently, however, $d p n$ expression precedes scrt in the CNS and in SMCs of the PNS. In contrast, scrt and sna have only partially overlapping expression patterns. Most S1 neuroblasts express sna before expressing scrt, but many neuronal progeny expressing scrt do not express sna. Also, sna is expressed in the support cells of chordotonal organs (CHO), whereas postmitotic scrt expression is restricted to the neuron. Similarly, double labeling of $d p n$ and sna reveals that many neuronal precursors in the CNS and PNS do not express sna at early stages of neuronal precursor formation (data not shown). Finally, sna differs from scrt and $d p n$ in that it is expressed in embryonic dorsal imaginal disc primordia and in abdominal histoblasts (Alberga et al. 1991).

To determine whether scrt might play a role in adult neurogenesis we examined scrt expression in the CNS of third-instar larvae and in imaginal discs. We observed that scrt is expressed in neuronal cells in the wing disc (Fig. 1I), in developing neurons in pupal wings (data not shown), in many cells posterior to the morphogenetic furrow in the eye-antennal disc (Fig. 1J), in a pattern resembling that of neuronal precursor cells in the leg that express the pan-neural gene asense (data not shown; Brand et al. 1993; Domínguez and Campuzano 1993), and in many cells in the third-instar larval brain and ventral nerve cord (data not shown). Similar to the situation in embryos, scrt and sna have overlapping but distinct neuronal expression patterns in imaginal discs: sna is expressed late in neurons of everting wing discs but not earlier in neuronal progenitors and is absent during larval stages of eye disc development.

scrt encodes a predicted five zinc finger protein with homology to sna

The genomic fragment including a pan-neural transcription unit was used to probe Drosophila genomic and embryonic cDNA libraries (see above and Materials and methods). Genomic clones were recovered and restriction mapped (Fig. 2), and several cDNAs were isolated and sequenced (see Materials and methods). A digoxigenin-labeled probe made from a cDNA containing a complete open reading frame hybridizes to a transcript ex- 



Figure 1. Pan-neural expression of scrt during embryogenesis. The pattern of scrt expression was determined by in situ hybridization using an anti-sense digoxigenin-labeled scrt genomic probe containing the complete scrt transcription unit, which includes one or more introns. A similar expression pattern is observed using a cDNA probe with the exception that nuclear transcripts are not as intensely labeled prior to cytoplasmic translocation of the mature message. In this and subsequent figures, anterior is to the left and dorsal is to the top, unless indicated otherwise, and the ventral midline is indicated by an arrowhead. Embryos are staged according to Campos-Ortega and Hartenstein (1985). (A) A ventral view of scrt expression in ectodermal cells in the region giving rise to the inner $\left(r_{1}\right)$ row of SI neuroblasts prior to delamination $(\sim 5-51 / 2 \mathrm{hr})$. (B) A ventral view of scrt expression in cells comprising the full SI wave of neuroblasts in an early germ-band-extended embryo $(-51 / 2 \mathrm{hr})$. Neuroblast rows are numbered $\mathrm{r}_{1}-\mathrm{r}_{3}$. $(C)$ scrt expression in an embryo at the same stage shown in $A$ viewed in sagittal section. The ectoderm $(\mathrm{e})$, mesoderm $(\mathrm{m})$, and neuroblasts $(\mathrm{n})$ are indicated. $(D) \mathrm{A}$ ventral view of scrt expression in a late germ-band-extended embryo $\left(\sim 6^{1 / 2} \mathrm{hr}\right)$. The majority of neuroblasts have delaminated by this stage. CNS labeling is solid by this stage (arrow), differing from the ring-like staining of neuroblasts observed with $d p n$ at the same stage (see $E$ ). Note the two PNS precursor cells located dorsal to the CNS (bracket). (E) dpn expression in neuroblasts at the same stage shown in $D$. This embryo has been flattened more than the embryo in $D$ during mounting, leading to an artifactual appearance of a broader CNS. At this stage, $d p n$ is expressed only in neuroblasts arranged in a ring (or rosette) with an unlabeled center (arrow). The first two PNS precursor cells that express $d p n$ at this stage are out of focus. $|F|$ scrt expression in most or all PNS precursors of a germ-band-retracting embryo $(\sim 81 / 2-9 \mathrm{hr})$. $(G)$ Pattern of $\beta$-galactosidase expression in dorsal (d), lateral (l), ventral prime $\left(\mathrm{v}^{\prime}\right)$, and ventral $(\mathrm{v})$ clusters of PNS neurons in germ-band-retracted embryos carrying a scrt P-lacW enhancer trap insertion. (Top) The embryo is viewed laterally; (bottom) the embryo is viewed ventrolaterally. $(H)$ A diagram of PNS cells, slightly modified from those of Ghysen et al. (1986), Bodmer and Jan (1987), and Hartenstein (1988) to account for the incomplete migration of neurons, is shown for reference. (I) scrt expression in a third-larval instar wing imaginal disc. (J) scrt expression in a third-instar larval eye-antenna imaginal disc. The morphogenetic furrow is denoted by an arrowhead.

pressed in the same pan-neural pattern as the genomic fragment used to screen the cDNA library. A Northern blot hybridized with the same cDNA probe reveals a single transcript of $6.5 \mathrm{~kb}$ present in 4- to $12-\mathrm{hr}$ embryos but absent in 0- to 4-hr embryos (data not shown), consistent with the expression pattern observed by wholemount in situ hybridization.
One of the longest cDNA clones contains a single long open reading frame predicting a protein of 664 amino acids (Scrt) with five zinc fingers near its carboxyl terminus (Fig. 3A). The predicted amino acid sequences of each of these zinc fingers show similarity to each other as well as to each of the five zinc fingers of the Sna protein, which is required for mesoderm determination, 


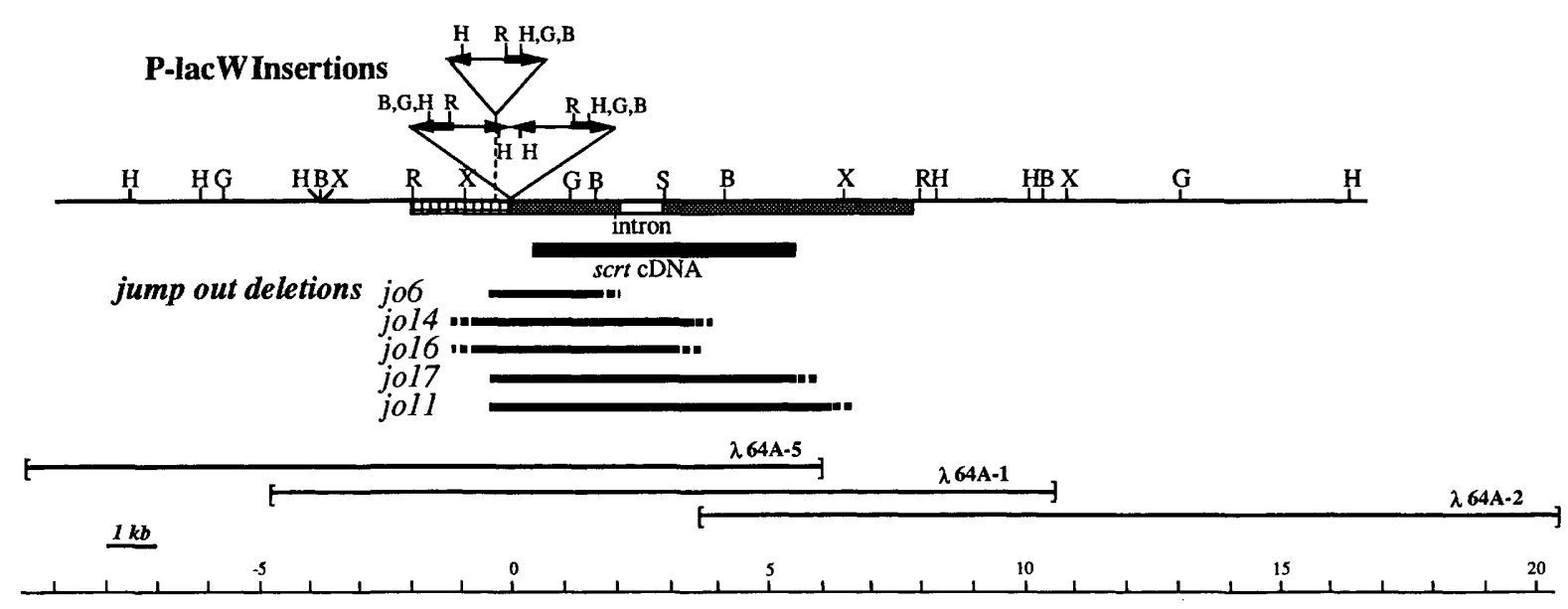

Figure 2. Molecular map of the scrt locus. Restriction map of the genomic region encompassing the scrt locus. Locations of a single and a double head-to-head P-lacW insertion site are indicated above the map. The region hybridizing to the longest scrt cDNA is shown immediately below the map. The extents of various $s c r t^{\text {io }}$ deletions are also indicated below the map as well as the limits of the genomic phage inserts covering the scrt locus.

and of the Escargot (Esc) protein, which controls polyploidy during imaginal disc growth (Fuse et al. 1994). In the most conserved stretch of 46 amino acids, Scrt exhibits $76 \%$ identity (and $87 \%$ similarity permitting only the most conservative changes) with Sna. Each zinc finger in Scrt most resembles its counterpart in the Sna and Esc proteins. Fingers 3 and 4 exhibit particularly high degrees of sequence similarity with runs of $12 / 13$ and 13/14 identical residues between Scrt and Sna. This high degree of sequence identity extends to proteins encoded by various vertebrate sna homologs (Fig. 3B).

\section{scrt collaborates with dpn to promote neurogenesis}

To determine the function of the scrt gene we selected for white minus transposase-induced revertants of one of the $\mathrm{P}-\mathrm{lacW}$ insertions into the scrt locus. Among these revertants, five imprecise jump-out excisions $\left(s c r t^{j o}\right)$ of the P-lacW element were recovered $\left(s c r t^{\mathrm{jo6}}, s c r t^{j \mathrm{j} 11}\right.$, $s c r t^{j 014}$, scrtio16, and scrtio17). Homozygous $s c r t^{i 011}$, $s c r t^{j 014}, s c r t^{j 016}$, and $s c r t^{j 017}$ escapers have a subtle but completely penetrant rough eye, frequently have scratched facets near the edge of the eye, hold their wings vertically under mild $\mathrm{CO}_{2}$ anesthesia, and are so weak and uncoordinated that they often get stuck in the food immediately after eclosion. Similarly, each of the $s c r t^{i o}$ chromosomes in trans to large deletions of the 64A region [Df(3L)HR277 and Df (3L)A466] show the same phenotypes. The scratched eye phenotype consists of black scars near the anterior margin of the eyes resembling scratched eye, a mutation that maps nearby in the 64C-E region (Lindsley and Grell 1968). The five $s c r t^{i o}$ revertants fail to complement each other, but do complement the scratched eye mutation. The recovery of five independent transposase-induced revertants causing similar eye defects suggests that a nearby gene contributes to normal eye development.

Southern blot analysis of the $s c r t^{j o}$ revertants indicates that they lack varying amounts of genomic DNA, including part or all of the scrt transcription unit (Fig. 2). Consistent with these findings, scrt expression is undetectable by in situ hybridization in embryos homozygous for the $s c r t^{j 011}, s c r t^{j 016}$, and $s c r t^{j 017}$ mutations and is greatly reduced in $s c r t^{j o 6}$ homozygous mutants. Because each of these transposase-induced lesions is associated with overlapping local deletions of the scrt transcription unit, we conclude that the complementation group defined by these revertants corresponds to the scrt gene.

The revertant carrying the largest deletion of scrt genomic sequences, $s c r t^{j 011}$, lacks all cDNA-coding sequences of the scrt gene and therefore represents a null mutation. Although homozygotes for this small deletion show low viability, they do eclose as adults under favorable conditions (see above) and are fertile in outcrosses. Embryos homozygous for the scrt ${ }^{\text {jo11 }}$ deletion exhibit no detectable morphological defects when examined carefully with a variety of tissue-specific markers including early neuronal precursor markers [e.g., ASC-T3, dpn, sna, Hunchback ( $\mathrm{Hb})$, and Prospero (Pros)], late postmitotic neuronal markers [embryonic lethal abnormal visual system (elav), anti-HRP, mAb22C10, Even-skipped (Eve), and, cho, a chordotonal organ neuron-specific marker], epidermal markers [orthodenticle (otd), Enhancer of split (E(spl)m7), Serrate (Ser), tramtrack (ttk), and $r h o$, and early and late muscle markers (nautilus and mbA6D9) (data not shown). Similarly, embryos homozygous for the $s c r t^{j 014}, s c r t^{j 016}$, and $s c r t^{j 017}$ mutations appear morphologically normal as do embryos trans-heterozygous for any of the five $s c r t^{\text {jo }}$ alleles in combination with either Df(3L)HR277 or Df (3L)A466 (data not shown).

As embryos lacking scrt function appear morphologically normal, we tested the possibility that scrt might collaborate with other genes to promote embryonic neurogenesis. Thus, we examined nervous system formation in embryos lacking other pan-neural genes in addition to 
Roark et al.

\section{A}

MPRCLIAKKWKAYPWLDRTEDTCNQQQQQEQSAPNSPREL

EELHLKSRRSTLDDDEEIDVVGDKFLIKLEKQRTTADAAAAAATSSEAATSHSSNSSNMEASATTTTSKCWGPSSPTAGT

TAPSPPPHSPEAATRVAGNVYNGYTRELSPLHYTAYLPRMESEITVIRAAATALVAARTSGNGSGDQHLAVYQTPPSSTT

SSPSCSFSGAGDRYSPLSSGQTSSERKCFSSTGATLSLPPKKKDIYRPYSLDDKPAHGYRRRVPAEEDLHAAHAILDLSA

STAFHPFTQPHQLQQQQQQQOQQHQHHHSOQOHLAFQQHHYLPLOQOOOOQAHHTHLTLEAHAHLRSTSSIAELAAAAS

VVNEQRPASNASSASSNHMPSSPSSNSSSSSSQVQNENSNTTNTNQDGDGCLQDGEHNGASGASAKTVAYTYEAFFVSDG

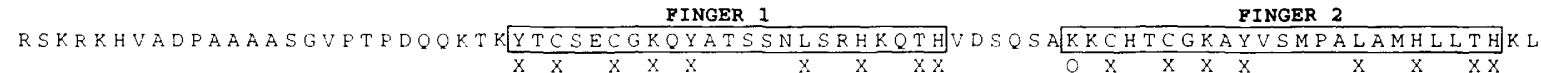

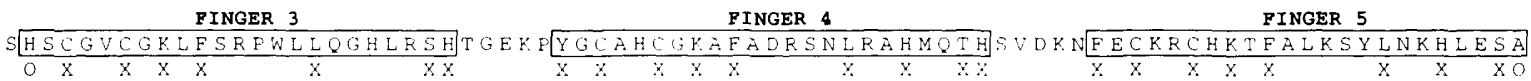

CLKDEEELMMSMSLSMHESNSESGASMASSEFHEFIAAROTRRAYEEPLMFCYHRTHWARYRNL

Figure 3. Sequence of the predicted Scrt product. (A) The predicted protein sequence derived from conceptual translation of cDNA sequences. Several clones obtained from Kuvar and Zinn embryonic cDNA libraries were sequenced, including one clone containing the full scrt open reading frame (Zinn library). (B) Alignment of zinc finger domains of Scrt, Drosophila Sna (Boulay et al. 1987), Xenopus Sna (Sargent and Bennett 1990), Drosophila Escargot (Whitely et al. 1992), and Chicken Slug (Nieto et al. 1994). Other Sna-related proteins not shown in the alignment include those isolated from zebrafish (Hammerschmidt and Nüsslein-Volhard 1993; Thisse et al. 1993) and mouse (Nieto et al. 1992; Smith et al. 1992). Boxed positions indicate amino acids for which a strong consensus sequence exists among the various zinc fingers. Stars indicate the invariant positions defining the larger family of zinc finger proteins to which the Sna/Scrt/Esc subgroup belongs. Boldface type indicates an amino acid residue that is most frequent at a given position within a particular zinc finger repeat. Italicized residues are similar to the consensus amino acid for that position. The GenBank accession number for the scrt sequence is U36477.

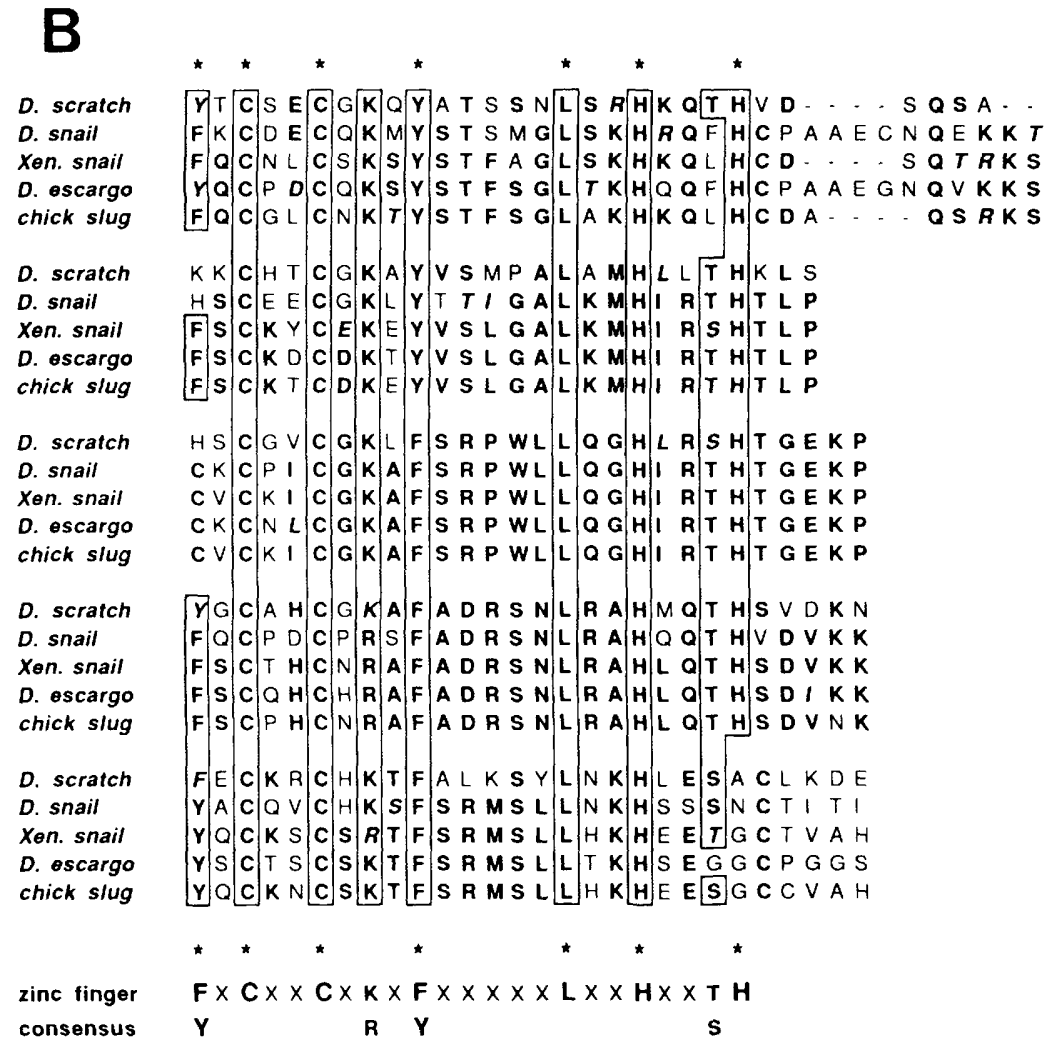

the various cell types of the nervous system. Further experiments utilizing a temperature-sensitive combination of hypomorphic sna alleles (P. Simpson, pers. comm.) will be required to analyze this question in greater detail.

We have also asked whether $d p n$ and scrt interact. These two genes have similar pan-neural expression patterns but encode unrelated proteins: Dpn contains a bHLH domain, whereas Scrt contains a zinc-finger domain. Loss of function of either of these two pan-neural genes alone does not lead to obvious morphological disruption of the embryonic nervous system [see above for $s c r t$, and Bier et al. (1992) for dpn]. Under optimal con- 
ditions, animals homozygous null for each of these genes occasionally complete development and eclose. In contrast, animals homozygous null for both genes never hatch and frequently exhibit a dramatic reduction of the nervous system (Fig. 4B,E,H). In the PNS of $d p n^{1}$; scrt $t^{j 011}$ double mutant embryos, where individual neurons can be identified, we consistently observed a reduction in the number of neurons labeled with $\mathrm{mAb} 22 \mathrm{ClO}$ (Fig. 4, cf. B and A), anti-HRP (data not shown), and cho (Fig. 4; cf. E and D). In addition, axon projections are frequently disorganized in $d p n^{1}$; scrt ${ }^{j o 11}$ double mutant embryos. $d p n^{1}$; $s c r t^{i 011}$ double mutant embryos also exhibit serious CNS defects such as missing and disorganized longitudinal and commissural axon tracks labeled with anti-HRP and loss of CNS neurons including a fraction of those expressing Eve (data not shown). CNS defects are evident early during neurogenesis as there are fewer $\mathrm{Hb}$ expressing cells contributing to the $\mathrm{S} 1$ wave of neuroblasts than in wild type embryos (Fig. 4, cf. H and G).

\section{Ectopic expression of scrt generates extra neurons}

The loss of neurons in embryos double mutant for scrt and $d p n$ described above and the reduction in photoreceptor number in scrt single mutants (see below) suggests that scrt promotes neuronal development. To test this hypothesis further we examined the consequence of ectopic scrt expression during embryogenesis. A HS-scrt construct in which the scrt-coding region is under control of the $h s p 70$ promoter in the $\mathrm{P}[\mathrm{hs}-\mathrm{CaSpeR}]$ vector (Bang and Posakony 1992) was introduced into flies by P-element-mediated transformation (Spradling 1986). The consequence of brief ubiquitous expression of scrt following heat induction was examined at a variety of developmental stages. A l-hr heat shock beginning at 3-5 hr of embryogenesis leads to an increase in cells staining with mAb22C10. Cuticle mounts of embryos heat-shocked at these times occasionally display duplicated external structures such as hairs or pits (data not shown). More frequently, we observe missing cuticular structures, such as campaniform sensilla, which may correspond to the transformation of secondary outer support cell precursors into inner neuronal/glial precursors (see adult data described below). Multiplication of mAb22C10 staining cells in the region of the developing chordotonal organs is a very penetrant phenotype of HSscrt embryos (Fig. 4C). The additional cells have a $\mathrm{CHO}$ neuronal identity (Fig. 4, cf. F and D). In addition, the lateral CHO clusters are often misplaced, and PNS axons follow abnormal pathways. HS-scrt embryos also have CNS defects. For example, the number of $\mathrm{Hb}$-expressing cells is greater than in wild-type embryos of comparable age (Fig 4, cf. I and G). The increase in the number of Hb-expressing neuroblasts results in part from a precocious appearance of primary neuronal precursor cells. Thus, Hb-, scute- (T4), achaete- (T5), and dpn-expressing neuroblasts first appear during early stages of germ-band extension in HS-scrt embryos (Fig. 4K,L: dpn $\sim 4 \frac{1 / 2}{\mathrm{hr}}$ ), more than an hour before neuroblast delamination or expression of neuroblast markers in wild-type embryos
(Fig. 1B, scrt; Fig. 4J, $d p n$ ). The very earliest time when subectodermal $d p n$-expressing cells can be observed in HS-scrt embryos is at the beginning of germ-band extension, when the most terminal stripe of $d p n$ pair-rule expression is still visible (data not shown). Reciprocally, expression of $d p n$ in proneural-like ectodermal patches prior to neuroblast delamination (Bier et al. 1992) is foreshortened in HS-scrt embryos. These patches have nearly disappeared before germ-band extension is $>50 \%$ complete (Fig. 4K,L). dpn and Hb expression in PNS precursors is also observed earlier than usual as SMCs are visible during the beginning of the extended germ-band stage when the SI stage of neuroblast delamination normally commences (Fig. 4I; bracket). This precocious expression of neuronal precursor markers is not a result of heat shock treatment, as heat-induced wild-type embryos express $\mathrm{Hb}$ and $d p n$ on schedule relative to morphological criteria such as extent of germ-band elongation (data not shown). It is possible that ectopic expression of scrt slows germ-band extension rather than accelerating neuroblast formation. We believe this to be unlikely, however, because the complex pattern of cells expressing rho and otd do so in step with the morphological measures of germ-band extension (data not shown). In the case of $r$ ho, the heat shock treatments were effective in these experiments because rho expression in tracheal pits was specifically reduced (see below). In addition, the fact that the proneural-like expression of $d p n$ is not shifted to an earlier period but, rather, is significantly foreshortened suggests that the cells that normally would express $d p n$ in the proneural pattern have prematurely made the neuroblast versus epidermal cell fate choice.

\section{scrt promotes adult neurogenesis}

Because a rough eye is the most penetrant loss-of-function scrt phenotype, we examined the effects of loss of scrt and ubiquitous scrt expression in the eye. Eyes of $s c r t^{i 011} / s_{c r} t^{i 011}$ homozygotes and of flies homozygous for the HS-scrt construct that had been heat-shocked for $1 \mathrm{hr}$ during the late third-larval instar were dissected, fixed, and sectioned. Flies homozygous for the scrt ${ }^{i o 1} 1$ deletion have a mild, but highly penetrant, rough eye phenotype. In superficial sections of the eye the pattern of lenses and interommatidial bristles is relatively normal (data not shown). In deeper sections passing through the apical regions of photoreceptor cells we frequently observe ommatidia with fewer than seven photoreceptor cells. In addition, many of the photoreceptors appear shrunken relative to wild type, the number of pigment cells is reduced, and the ommatidial units are often broken and abnormally spaced. The shrunken cell phenotype becomes progressively more obvious in deeper sections where large empty spaces are observed between ommatidia (Fig. 5, cf. B and A).

In contrast to the loss of photoreceptor cells observed in $s c r t^{i 011}$ homozygous eyes, ommatidia of heat-shocked HS-scrt flies frequently have eight rather than seven photoreceptor cells (Fig. 5C). This extra cell may be a 

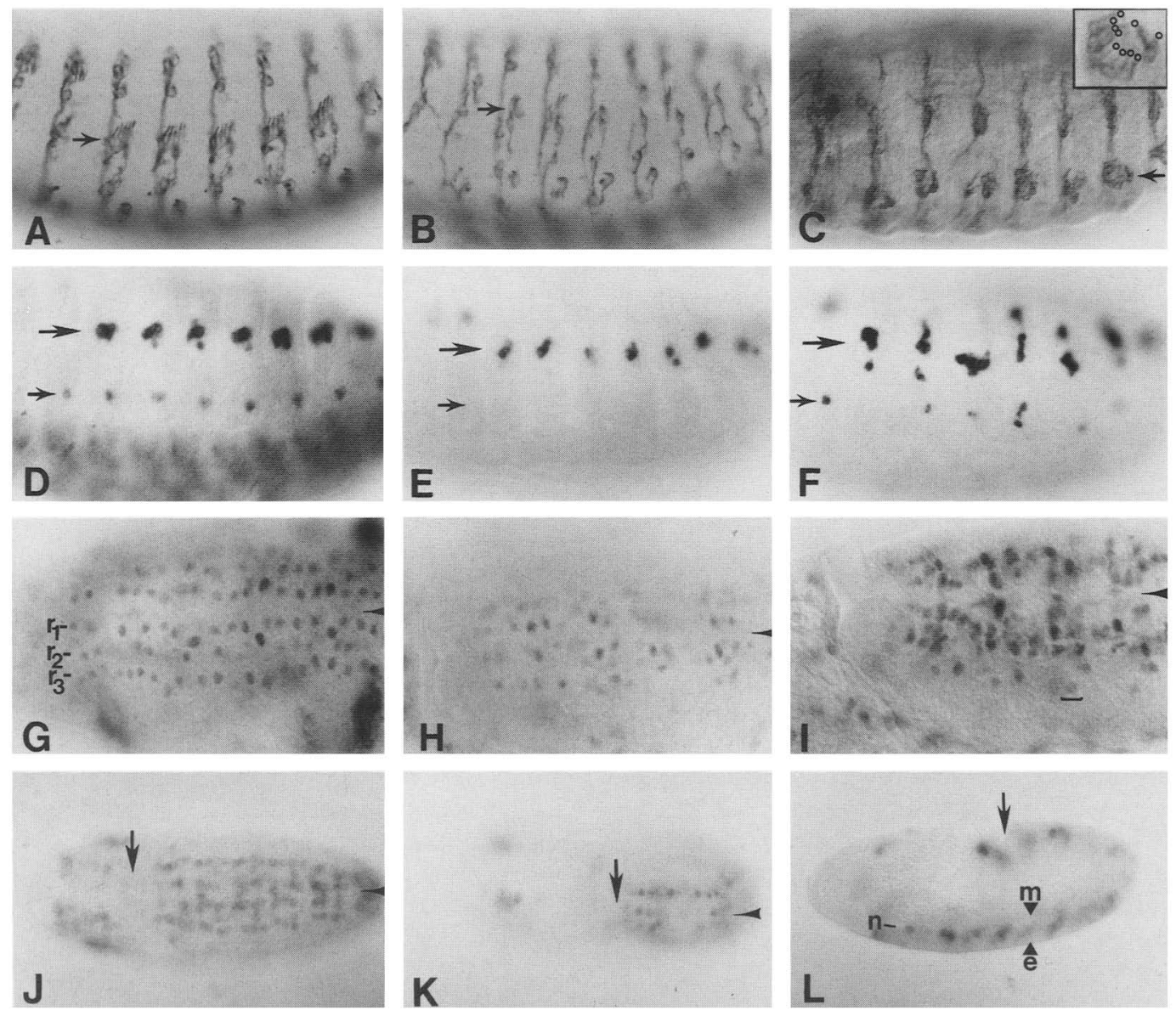

Figure 4. Embryonic scrt phenotypes. The neuronal loss phenotype of $d p n$; scrt double mutant embryos was observed in collections of $d \mathrm{pn}^{1} /$ Cyoftz-lacZ; scrt ${ }^{j 011} / T M 6 A b d A-l a c Z$ and Df(2L)193A/Cyoftz-lacZ; scrt ${ }^{\prime 011} / T M 6 A b d A-l a c Z$ balanced stocks $[D f(2 L) 193 A$ eliminates the $d p n$ gene]. Only double mutant embryos without any $\beta$-galactosidase protein expression exhibited the loss of neuron

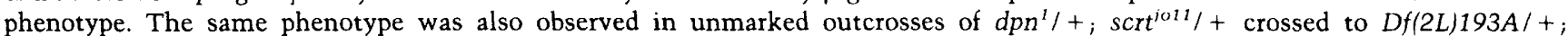
$s c r t^{i 017} /+$ flies in which double mutant embryos were scored by the absence of scrt and dpn RNA expression (data not shown). (A) A wild-type germ-band-retracted embryo $(\sim 14 \mathrm{hr})$ stained with the mAb22C10 antibody. The arrows in $A-C$ point to the location of the lateral CHO cluster. $(B) \mathrm{A} d p n^{1}$; scrt ${ }^{i 011}$ double homozygous mutant embryo stained with mAb22C10 has reduced numbers of labeled cells in each cluster. $(C)$ A HS-scrt embryo heat-shocked for $1 \mathrm{hr}$ at 5-6 hr of development and aged for $7 \mathrm{hr}$ at $25^{\circ} \mathrm{C}$ has an increased number of $\mathrm{mAb} 22 \mathrm{Cl0}$-labeled cells. The lateral $\mathrm{CHO}$ cluster indicated by the arrow is magnified (inset) to show $10 \mathrm{CHOs}$ (wild-type embryos have 6 CHOs in this region). (D) A wild-type embryo hybridized with a CHO neuron-specific probe (cho; L. Ditmer and L.J. Deftos, unpubl.). The large arrow indicates the position of the lateral CHO cluster (containing $6 \pm 0$ neurons; $n=10$ hemisegments); the small arrow indicates the position of the two ventral CHOs (see diagram in Fig. $1 \mathrm{H}$ for the relative position of these cells with respect to other neurons). Arrows point to the same positions in $D$ and $E$. (E) A $d p n^{1} ; s c r t^{i 011}$ double homozygous mutant embryo hybridized with the cho probe. Note the complete loss of ventral $\mathrm{CHOs}$ and the severe reduction in number in lateral $\mathrm{CHOs}$ (average $=3$ neurons $\pm 1 ; n=50$ hemisegments). (F) cho expression in a HS-scrt embryo heat-shocked for $1 \mathrm{hr}$ at $5-6 \mathrm{hr}$ of development and aged for $7 \mathrm{hr}$ at $25^{\circ} \mathrm{C}$. Note the increased number of labeled cells in both lateral (average $=8$ neurons $\pm 1 ; n=50$ hemisegments) and ventral clusters. These clusters are also no longer located in stereotyped positions. $(G)$ Expression of Hb protein in neuroblasts of a wild-type embryo $(\sim 51 / 2 \mathrm{hr})$ in which the S1 wave of neuroblasts has delaminated and the first S2 neuroblasts have formed (at this stage Hb is detectable in an average of $37 \pm 1$ cells per 4 hemisegments; $n=24$ hemisegments). Neuroblast rows $r_{1}-r_{3}$ also are indicated. (H) Hb expression in a $d p n^{1} ; s c r t^{i o 11}$ double mutant embryo at the same stage as shown in $G$. Fewer cells express $\mathrm{Hb}$ (average $=27 \pm 3$ cells per 4 hemisegments; $n=24$ hemisegments) indicating that neuroblasts are either missing or abnormal. (I) Hb expression in a HS-scrt embryo heat-shocked for $1 \mathrm{hr}$ at $4 \mathrm{hr}$ of development and aged for $1 \mathrm{hr}$ at $25^{\circ} \mathrm{C}$. More $\mathrm{Hb}$-positive cells are observed than in wild-type embryos at a similar stage of germ-band elongation (average $=52 \pm 5$ cells per 4 hemisegments; $n=32$ hemisegments). (J) A ventral view of dpn expression in SI neuroblasts in a wild-type germ-band-extended embryo. The arrow marks the posterior end of the germ band that is in contact with the back of the head. $(K)$ A ventral view dpn expression in a HS-scrt embryo that was heat-shocked for 1 hr at $3 \mathrm{hr}$ of development and aged for $1 \mathrm{hr}$ at $25^{\circ} \mathrm{C}$. The arrow marks the posterior end of the germ band that has not progressed beyond $50 \%$ elongation. $(L) d p n$ expression in a HS-scrt embryo similar to that shown in $K$ but viewed in sagittal section. The arrow marks the posterior end of the germ band. (e) Outer ectodermal layer; $(n)$ neuroblast layer; $(m)$ inner mesoderm layer. 

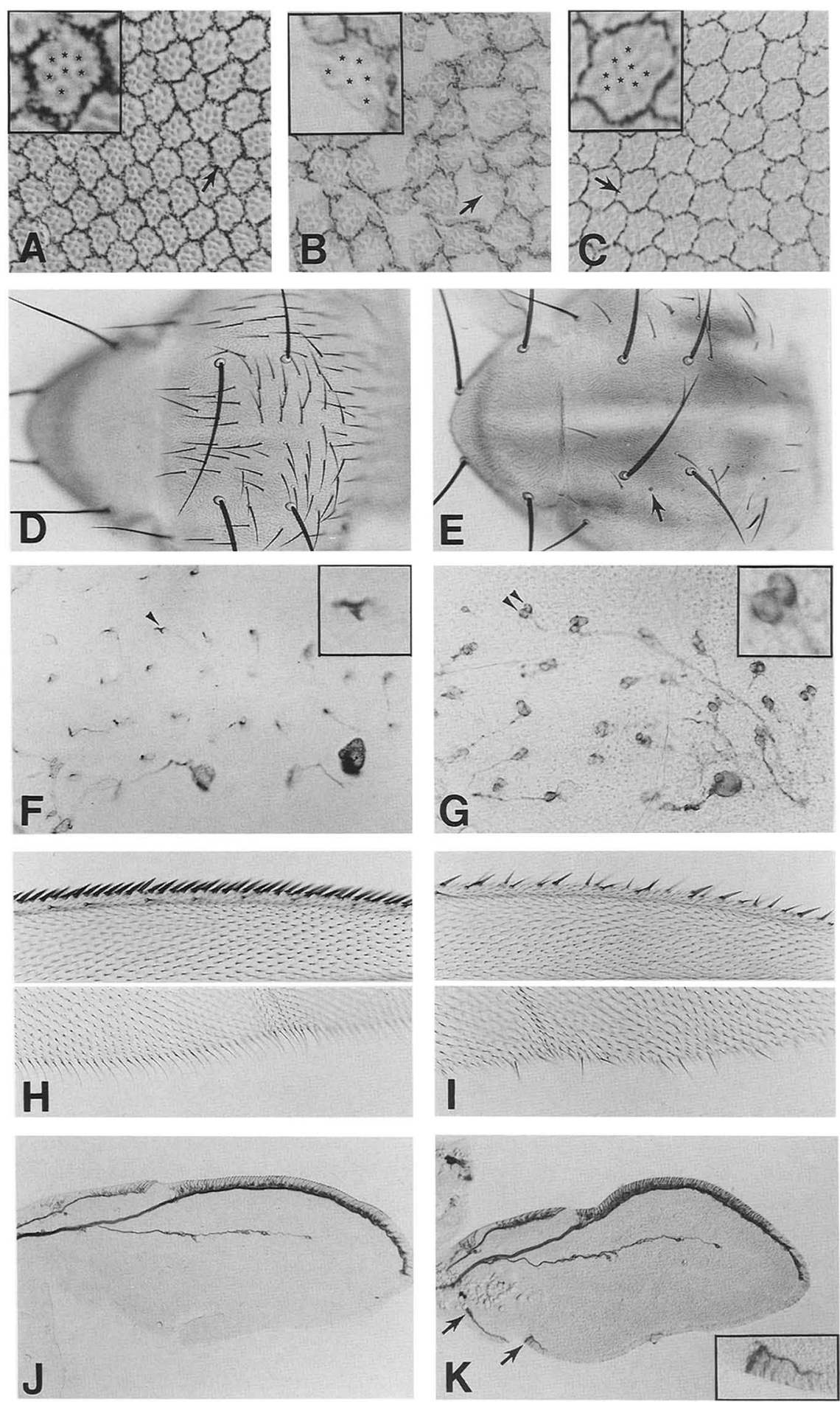
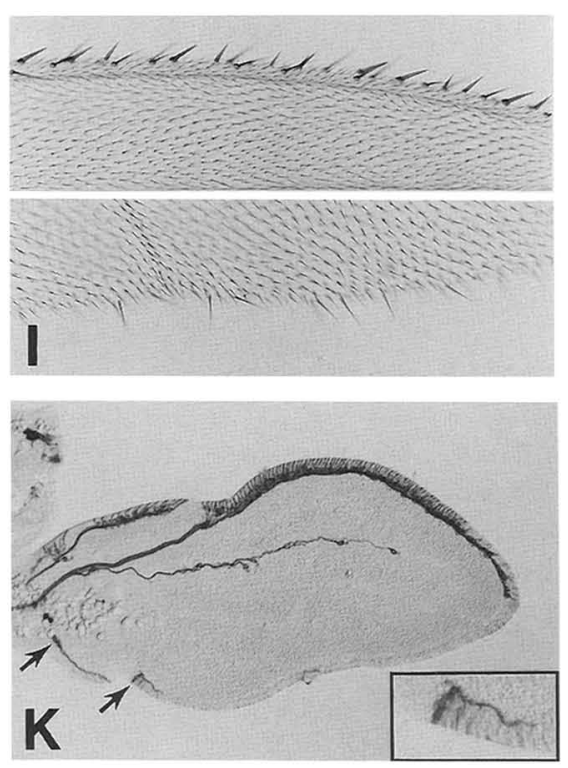

Figure 5. Adult scrt phenotypes. (A) A section through a wild-type adult eye showing the organized arrangement of photoreceptor and support cells in the ommatidial array. Note the stereotyped pattern of seven photoreceptor rhabdomeres in each ommatidial unit (e.g., arrow and inset). (B) A section through a scrt ${ }^{j o 11} \mathrm{mu}$ tant eye showing a reduction in photoreceptor cell number in a fraction of ommatidia (arrow, inset) and large empty spaces between ommatidial units. Rhabdomeres also appear shrunken relative to wild type. (C) A section through a HS-scrt eye heatshocked during the late third-larval instar. An extra rhabdomere is present in most ommatidial assemblies (arrow, inset). (D) The wild-type pattern of bristles on thorax. (E) A HS-scrt thorax with missing bristles resulting from heat-shock at $12 \mathrm{hr}$ AP. Note that in some cases the socket is still present (arrow). $(F)$ Thoracic neurons labeled with $\mathrm{mAb} 22 \mathrm{C} 10$ in a wild-type pupa. Each bristle has one strongly labeled neuron (arrowhead, inset). $(G)$ Duplicated thoracic neurons (arrowheads, inset) in a HS-scrt pupae resulting from heat shock treatment at $15 \mathrm{hr} \mathrm{AP} .(\mathrm{H})$ The wild-type pattern of bristles at the anterior $(t o p)$ and posterior (bottom) wing margins. The anterior margin is lined with sensory bristles, whereas noninnervated bristles border the posterior margin. (I) Pattern of marginal bristles in a HS-scrt fly heatshocked at $12 \mathrm{hr}$ AP. Many bristles are missing from both the anterior (top) and posterior (bottom) margins. (J) Neurons and axons labeled by $\mathrm{mAb} 22 \mathrm{C} 10$ in a wildtype pupal wing are packed densely along the anterior margin but are absent from the noninnervated posterior margin. $(K) \mathrm{A}$ HS-scrt wing labeled with $\mathrm{mAb} 22 \mathrm{C} 10$ showing three neurons and posteriorly directed processes emanating from the posterior margin (arrows, inset). particular photoreceptor cell that is duplicated, an accessory cell converted to a neuronal fate, or a misplaced $\mathrm{R} 8$ cell. scrt also collaborates with $d p n$ during photoreceptor development as well as during embryogenesis (see above) because $d p n /+$; scrt ${ }^{j o 11} / s c r t^{j o 11}$ have an enhanced rough eye phenotype and have a more severe loss of photoreceptor phenotype than typically observed for $s c r t^{i 011 /}$ $s c r t^{\text {o11 }}$ alone (data not shown). This interaction between $s c r t$ and $d p n$ is noteworthy, as eyes of homozygous $d p n$ flies appear normal (data not shown).

We performed a series of timed heat induction experiments to identify specific developmental stages when restricting scrt expression to the developing nervous system is essential (Table 1). Thus, heat shocks adminis- 
Table 1. Adult phenotypes from heat shocks during imaginal development

\begin{tabular}{|c|c|c|c|c|c|c|c|c|c|c|c|c|c|c|c|c|c|}
\hline Phenotype $^{a}$ & Stage: ${ }^{b}$ & $\begin{array}{l}1 \mathrm{i} \\
2 \mathrm{i}\end{array}$ & $\begin{array}{l}3 \mathrm{i} \\
\mathrm{f}\end{array}$ & $\begin{array}{l}3 i \\
w\end{array}$ & $\begin{array}{l}0 \\
\mathrm{hr}\end{array}$ & $\begin{array}{l}3 \\
\mathrm{hr}\end{array}$ & $\begin{array}{l}6 \\
\mathrm{hr}\end{array}$ & $\begin{array}{l}9 \\
\mathrm{hr}\end{array}$ & $\begin{array}{l}12 \\
\mathrm{hr}\end{array}$ & $\begin{array}{l}15 \\
\mathrm{hr}\end{array}$ & $\begin{array}{l}18 \\
\mathrm{hr}\end{array}$ & $\begin{array}{l}21 \\
\mathrm{hr}\end{array}$ & $\begin{array}{l}24 \\
\mathrm{hr}\end{array}$ & $\begin{array}{l}27 \\
\mathrm{hr}\end{array}$ & $\begin{array}{l}30 \\
\mathrm{hr}\end{array}$ & $\begin{array}{l}33 \\
\mathrm{hr}\end{array}$ & $\begin{array}{l}36 \\
\mathrm{hr}\end{array}$ \\
\hline Extra macrochaetae: $d$. thorax & & 4 & 3 & 21 & & & & 1 & & & & 4 & & & & & \\
\hline Rough eyes & & & & 100 & 97 & 45 & & & & & & & & & & & \\
\hline Missing macrochaetae: head & & & & & 43 & 82 & & 4 & 2 & 16 & & & & & & & \\
\hline d. thorax & & & & & 43 & 45 & & & & 4 & & & & & & & \\
\hline scutellum & & & & & 73 & 64 & & 1 & & 5 & & & & & & & \\
\hline sternopleurals & & & & & 53 & 18 & & & & 4 & & & & & & & \\
\hline Missing wing margin bristles & & & & & & & & & 94 & 78 & & & & & & & \\
\hline Missing microchaetae: head & & & & & & & & & 8 & $45 a$ & $51 \mathrm{a}$ & $13 a$ & & & & & \\
\hline $\begin{array}{l}\text { d. thorax } \\
\text { sternopleurals }\end{array}$ & & & & & & & & 3 & & $\begin{array}{l}75 b \\
65\end{array}$ & $93 b^{*}$ & $73 b$ & & & & & \\
\hline $\begin{array}{l}\text { Missing bristles: legs } \\
\text { abdomen }\end{array}$ & & & & & & & & & & 49 & 29 & 9 & $97 \mathrm{c}$ & $100 \mathrm{c}$ & $19 \mathrm{c}$ & & \\
\hline Missing posterior crossvein & & & & & & & & 94 & & 24 & 64 & 67 & 100 & 89 & & & \\
\hline Total no. scored & & 23 & 71 & 14 & 30 & $11 !$ & $2 !$ & 69 & 50 & 55 & 45 & 45 & 39 & 53 & 53 & 55 & 54 \\
\hline
\end{tabular}

Larvae or pupae of various stages were collected onto wet Whatman filter paper in petri dishes and heat-shocked at $38^{\circ} \mathrm{C}$ by floating in a circulating water bath. Data are expressed as the percentage of animals showing the phenotype out of the total number scored. a(d. thorax) Dorsal thorax.

${ }^{b}$ (Stage) The time that the first of two 45 -min heat shocks was begun (the two heat shocks were separated by $1 \mathrm{hr}$ ). (hr) Hours after puparium formation, where $0 \mathrm{hr}=$ white prepupal stage; $1 \mathrm{i}, 2 \mathrm{i}$, and $3 \mathrm{i}=$ first-, second-, and third-instar larvae; $\mathrm{f}=$ feeding; and $\mathrm{w}=$ wandering. (a) Interocular and frontal head microchaete were counted for wild-type flies (18 \pm 1 bristles, $n=8)$, for HS-scrt flies heat-shocked beginning at $15 \mathrm{hr}$ AP $(11 \pm 3$ bristles, $n=10)$, for HS-scrt flies heat-shocked beginning at $18 \mathrm{hr}$ AP ( $8 \pm 2$ bristles, $\mathrm{n}$ $=10)$, and for HS-scrt flies heat-shocked beginning at $21 \mathrm{hr}$ AP $(13 \pm 2$ bristles, $n=7)$. (b) Microchaete on the dorsal thorax bounded by the four dorsocentral macrochaete were counted for wild-type flies $(41 \pm 3$ bristles, $n=10)$, for HS-scrt flies heat-shocked beginnig at $15 \mathrm{hr}$ AP $(19 \pm 6$ bristles, $n=10)$, for HS-scrt flies heat-shocked beginning at $18 \mathrm{hr} \mathrm{AP}(1 \mathrm{l} \pm 5$ bristles, $n=10)$, and for HS-scrt flies heat-shocked beginning at $21 \mathrm{hr} \mathrm{AP}(19 \pm 6$ bristles, $n=10)$. (c) Bristles on the fourth abdominal sternite were counted for wild-type flies $(20 \pm 2$ bristles, $n=10)$, for HS-scrt flies heat-shocked beginning at $24 \mathrm{hr}$ AP $(14 \pm 3$ bristles, $n=10)$, for HS-scrt flies heat-shocked beginning at $27 \mathrm{hr} \mathrm{AP}(10 \pm 3$ bristles, $n=10)$, and for HS-scrt flies heat-shocked beginning at $30 \mathrm{hr}$ AP (13 \pm 4 bristles, $n=8) .\left({ }^{*}\right)$ Most of the sites of missing bristles still had sockets present; (!) the number of flies recovered in this and a previous experiment are consistently low for heat shocks in this time window (this may indicate a highly penetrant lethality).

tered just before the time of puparium formation lead to a rough eye phenotype (see above), induction at the time of puparium formation [0 $\mathrm{hr}$ after pupariation (AP)] causes significant loss of macrochaete on the thorax and head, and heat shocks at later times (starting at $9 \mathrm{hr} \mathrm{AP}$ and peaking at $12-15 \mathrm{hr} \mathrm{AP} /$ produce a dramatic loss of microchaete from the thorax (Fig. 5, cf. E and D) and head. In addition, these animals have missing bristles on several segments of the legs (particularly the femur; data not shown), missing bristles and hairs around the anterior and posterior wing margin (Fig. 5, cf. I and H), and missing interommatidial bristles over large areas of the eye (data not shown). In some cases, empty sockets remain where a bristle would ordinarily form (Fig. 5E, arrow). Animals heat-shocked at still later times (beginning at $15 \mathrm{hr}$ AP and peaking at $24 \mathrm{hr}$ AP) lack virtually all macrochaete and microchaete on the abdomen, lack part or all of the posterior crossvein, and, with less frequency, lack the anterior crossvein (Table 1). There is occasional twinning and duplication of bristles preceding and overlapping each of these periods of bristle loss (Table 1).

To examine the basis for the bristle loss phenotype pupae staged to $15 \mathrm{hr}$ AP were heat-shocked, aged for 10 $\mathrm{hr}$, and processed for staining with the PNS marker $\mathrm{mAb} 22 \mathrm{C} 10$. Such preparations show duplication of neu- rons at the locations where single microchaete normally would develop in the notum (Fig. 5, cf. G and F). In the developing pupal wing, cells along the posterior margin, which normally produce noninnervated bristles, stain with $\mathrm{mAb} 22 \mathrm{C} 10$ and extend axons (Fig. 5, cf. $\mathrm{K}$ and $\mathrm{J}$, indicating that cells that would otherwise differentiate as epidermal derivatives have been converted to neurons. Because adults derived from pupae that were heatshocked at $15 \mathrm{hr}$ AP show missing bristles on the thorax and along the wing margin, we conclude that ectopic expression of $s c r t$ most likely causes prospective glia or epidermal components of the sense organ to assume neuronal fates.

Loss of function and misexpression of scrt have opposite effects on target gene expression suggesting that scrt acts as a transcriptional repressor

As scrt is likely to encode a transcription factor we tested the effects of altered scrt function on the expression of various marker genes during embryogenesis. The Egf-r gene is one example of a potential scrt target gene. Normally, Egf-r is expressed in the mesodermal and ectodermal cell layers of the germ-band-extended embryo (Kammermeyer and Wadsworth 1987; Zak et al. 1990; Katzen et al. 1991; Zak and Shilo 1992; Sturtevant et al. 
1994) but is excluded from the neuroblast layer (Fig. 6A). In scrt null animals, however, ectopic Egf-r expression is observed at low levels in most neuroblasts and at high levels in occasional neuroblasts (data not shown). Ectopic expression of Egf-r in the neuroblast layer is significantly stronger and more penetrant in $d p n^{1}$; scrt ${ }^{j 011}$ double mutant embryos (Fig. 6B), whereas neuron specific markers (e.g., $\mathrm{Hb}$, sna, Pros, anti-HRP, Eve, $\mathrm{mAb} 22 \mathrm{C} 10$, and chol are expressed normally in the reduced number of neuronal cells. otd, another marker normally expressed only in epidermal cells during germband extension, also is ectopically expressed in neuroblasts in $d p n^{1}$; scrt $t^{j o 11}$ double mutant embryos (data not shown). Reciprocally, heat-induced HS-scrt animals exhibit a dramatic loss of Egf-r staining in the ectoderm, although mesodermal expression remains unaffected (Fig. 6C). Similarly, expression of both rho and Ser is repressed in developing tracheal cells in heat-induced HS-scrt embryos, whereas other epidermal components of these gene expression patterns remain unaffected /data not shown). Epidermal expression of $t t k$, however, is not obviously affected in either $d p n^{1}$; scrt $t^{\text {io } 11}$ double mutant embryos or in heat-induced HS-scrt animals (data not shown). Other than an increase in the number of neuronal cells in HS-scrt heat-induced embryos (as assayed by various markers; see above), non-neuronal cells such as

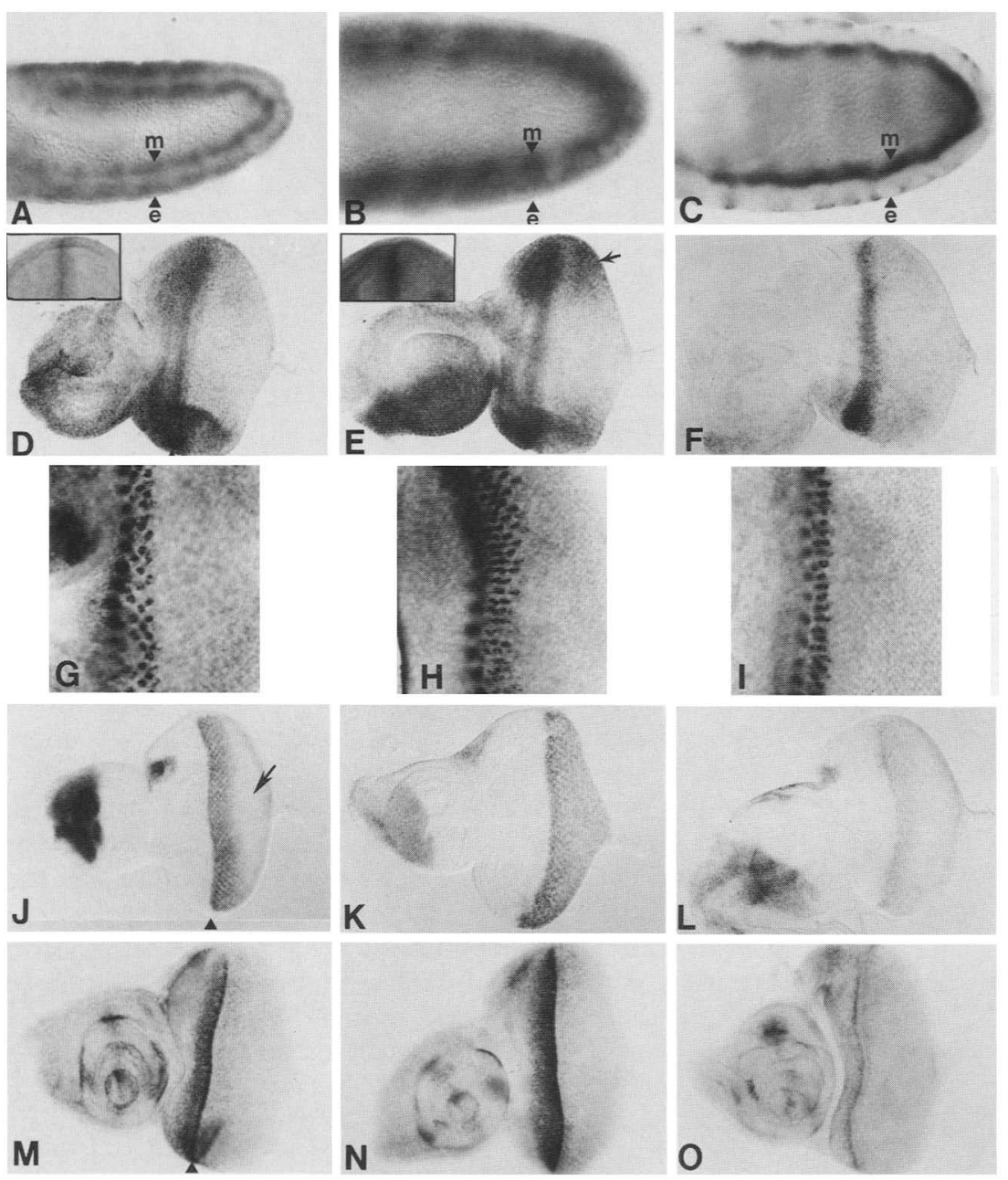

Figure 6. Alterations in gene expression patterns because of loss of function or misexpression of scrt. (A) Pattern of Egf-r expression in a wild-type germ-band-extended embryo. Egf $-r$ is expressed strongly in both the ectoderm (e) and in the mesoderm $(\mathrm{m})$ but is present at much lower levels in the neuroblast layer. (B) Egf-r expression in a $d p n^{1}$; scrt ${ }^{\text {ion } 11}$ homozygous double mutant extends into the neuroblast layer. $(C)$ Egf-r expression in a HS-scrt embryo that received a $1-\mathrm{hr}$ heat shock at 4-5 hr of development and was allowed $1 \mathrm{hr}$ of recovery at room temperature prior to fixation and staining. Note that virtually all epidermal staining is eliminated. Similarly heat-shocked control embryos have the wild-type pattern of $E g f-r$ expression, although at slightly reduced levels. (D) Egf-r expression in a wild-type eye disc. Anterior is to the left and dorsal is at the top. Note that staining is most intense at the morphogenetic furrow but also is expressed at significant levels posterior to the furrow. (Inset) The EGF-R protein pattern in the dorsal portion of the disc. (E) Egf-r expression in a $s c r t^{i o l l}$ mutant eye disc. Labeling posterior to the furrow is significantly elevated relative to wild type (arrow). This is most evident in the pattern of EGF-R protein expression (inset). $\{F \mid$ Egf- $r$ expression in a HS-scrt eye disc following $1 \mathrm{hr}$ of heat shock and 45 min of recovery. Egf-r expression is reduced significantly, particularly posterior to the morphogenetic furrow. Uninduced HS-scrt eye discs or heat-induced wild-type eye discs have the wild-type pattern of Egf-r expression. $(G)$ scabrous expression in a wild-type eye disc. Typically, three rows of cells in and posterior to the furrow are labeled at this stage. $(H)$ scabrous expression in a $s c r t^{j o 11}$ mutant eye disc is expanded in the posterior direction to approximately five rows of labeled cells posterior to the furrow. $(I)$ scabrous expression in a HS-scrt eye disc following 1 $\mathrm{hr}$ of heat shock and $45 \mathrm{~min}$ of recovery is reduced to one to two rows of labeled cells posterior to the furrow. $(J) h h$ is expressed in a domain posterior to the furrow in a wild-type eye disc. Expression in the more differentiated region of the disc has faded by this time generating a relatively unstained posterior domain (arrow). $(K)$ h h expression in a scrt ${ }^{\text {io1 }}$ mutant eye disc is expanded in the posterior direction to include nearly all clusters virtually eliminating the unstained posterior domain. $(L) h h$ expression in a HS-scrt eye disc following $1 \mathrm{hr}$ of heat shock and $45 \mathrm{~min}$ of recovery is reduced relative to wild type. The unstained posterior domain is larger than in comparable wild-type discs. Expression in the antennal portion of the disc is less affected by HS-scrt expression, providing an internal control for staining efficiency. $(M)$ hairy expression in a wild-type eye disc. Note that much of the hairy expression domain is anterior to the furrow. $(N)$ hairy expression in a scrt ${ }^{j 11}$ mutant eye disc is significantly expanded in the anterior direction relative to wild type. (O) hairy expression in a HS-scrt eye disc following $1 \mathrm{hr}$ of heat shock and $45 \mathrm{~min}$ of recovery is reduced relative to wild type. 
epidermal or muscle cells do not express inappropriately any neuronal marker tested.

Because scrt null and HS-scrt mutant animals have opposite defects in photoreceptor number and because scrt normally is expressed in photoreceptor cells of the developing eye (Fig. 1J), we also examined expression of various characterized markers during eye development in these mutants. Digoxigenin-labeled RNA probes for various genes were hybridized to developing eye imaginal discs of wild-type animals (with or without heat induction), scrt ${ }^{i 011}$ homozygotes, and HS-scrt flies (heatshocked for $1 \mathrm{hr}$ prior to fixing and staining of discs). For each marker, labeling of heat-shocked and non-heatshocked wild-type discs was indistinguishable /data not shown).

In the absence of scrt, the number of cells in the differentiating field of ommatidia-expressing Egf- $r$ RNA is increased (Fig. 6, cf. E and D). This is reflected by an increase of Egf-r mRNA (detected by in situ hybridization) and by elevated EGF-R protein (revealed by antibody staining; insets in Fig. 6D,E). Conversely, when scrt is overexpressed via heat shock, Egf-r RNA levels are reduced (Fig. 6F).

To examine events within, behind, and in advance of the furrow we probed eye discs for expression of genes such as scabrous (sca), hedgehog (hh), decapentaplegic $(d p p)$, and hairy (Fig. 6G-O). For both the sca and $h$ h probes, loss of scrt function results in an increased number of cells in the differentiating field behind the furrow expressing the marker (Fig. 6, cf. $\mathrm{H}$ and $\mathrm{G}$ for $s c a$; and Fig. 6 , cf. $\mathrm{K}$ and $\mathrm{J}$ for $h h$ ). Conversely, ectopic expression of scrt results in fewer cells expressing sca (Fig. 6, cf. I and G) or $h h$ (Fig. 6, cf. L and J). dpp expression in $s c r t^{\prime o 11}$ or HS-scrt eye discs, however, is indistinguishable from wild type.

Expression of hairy is also altered in response to scrt. Loss of scrt function leads to increased levels of hairy RNA in cells immediately anterior to the furrow (Fig. 6, cf. $\mathrm{N}$ and $\mathrm{M}$ ), whereas ectopic scrt leads to dramatically reduced levels of hairy RNA (Fig. 6O). The loss-of-function effect must be indirect, as hairy expression is altered anterior to the morphogenetic furrow, where cells normally do not express scrt.

\section{Discussion}

\section{scrt promotes neuronal development}

A variety of evidence suggests that the normal function of the scrt gene is to promote neuronal development. Consistent with a role in specifying neuronal cell fates, scrt expression is restricted to the nervous system at all developmental stages examined. Although embryos homozygous for null scrt alleles appear morphologically normal and can survive to adulthood if cultured with care, adult $s c r t^{j o 11}$ escapers have slightly roughened eyes reflecting a reduction in photoreceptor number. Deeper within the eye the $s c r t^{j o 11}$ mutant phenotype is much more severe, with large spaces separating broken ommatidial clusters. In addition, there are genetic interactions between scrt and $d p n$, another pan-neural gene, which aggravate the adult eye phenotype. The synergistic action of $d p n$ and scrt is particularly striking in $d p n^{1}$; $s c r t^{j 011}$ homozygous double mutant embryos that have significant reductions in neuron number. Consistent with loss-of-function scrt phenotypes leading to neuron loss, ectopic expression of scrt leads to the production of supernumerary neurons during embryogenesis and development of the adult nervous system. These data suggest that scrt normally plays a role in promoting neurogenesis but that additional genes (e.g., dpn) act in parallel with scrt. The strong genetic interaction between scrt and $d p n$ provides evidence that $d p n$ is also likely to play a role in promoting nervous system development.

\section{scrt represses expression of target genes}

scrt encodes a zinc finger protein related to the products of the sna and esc genes, which have been shown to repress expression of various target genes (Kosman et al. 1991; Leptin et al. 1991; Rao et al. 1991; Ip et al. 1992; Fuse et al. 1994). We have examined the expression of a variety of neuronal and non-neuronal markers in mutants lacking scrt and in HS-scrt individuals induced to express scrt ubiquitously to determine whether scrt might function analogously as a repressor of non-neuronal genes. These experiments have identified several potential scrt target genes such as the Egf-r gene. Ectopic Egf-r expression is sporadically observed in the neuroblast layer of scrt mutant embryos. This phenotype is enhanced in $d p n^{1}$; scrt ${ }^{i \omega 11}$ double mutant embryos suggesting that $d p n$ also contributes to repression of Egf-r expression in the nervous system. Egf-r also is expressed at higher than normal levels in developing photoreceptor cells in $s c r t^{j 011}$ eye discs. Reciprocally, Egf-r is strongly down-regulated in epidermal cells when scrt is expressed ubiquitously during embryogenesis or adult development.

In general, loss of $s c r t$ function leads to ectopic expression of potential target genes, whereas, reciprocally, ubiquitous scrt expression leads to a reduction in expression of these genes. Because scrt functions to promote the formation of neurons at the level of cell fate specification, we propose that scrt represses transcription of genes such as Egf- $r$ that promote the establishment of non-neuronal cell fates. In contrast, expression of all neuronal markers we have examined is normal in $s c r t^{j 011}, d p n^{1} ; s c r t^{j o 11}$, and HS-scrt embryos. These data are consistent with Scrt acting like Sna and Esc to repress expression of target genes. However, more potential direct target genes must be identified and the cisacting elements of putative scrt responsive genes must be analyzed for functional scrt repressor binding sites to establish direct repression as a mechanism of scrt action.

Whereas some of the effects that we observe on gene expression patterns may be attributable to the direct action of scrt as a transcription factor, the anterior expansion of hairy expression in $s c r t^{j 011}$ eye discs must be indirect because cells anterior to the furrow normally do not express scrt. It is possible that the expansion of $h h$ 
expression posterior to the furrow in $s c r t^{j 011}$ mutants plays some role in mediating this effect, although existing data support models in which $\mathrm{Hh}$ diffusing over a short distance induces expression of $d p p$, which in turn encodes a long-range signal to promote furrow progression (Heberlein et al. 1993; Ma et al. 1993). Interestingly, a recent role for hairy in combination with extramacro. chaete $(e m c)$ in eye development suggests that these negative regulators of neurogenesis function to retard progression of the furrow (Brown et al. 1995). Thus, scrt expression posterior to the furrow may promote indirectly furrow progression by suppressing expression of signals required for activating genes such as hairy ahead of the furrow, which slow furrow progression. The precocious appearance of neuroblasts and primary PNS precursor cells in HS-scrt embryos similarly could be explained by models in which scrt functions normally to initiate neurogenesis, perhaps by repressing expression of genes that antagonize neurogenesis.

It is worth noting that pan-neural expression of several vertebrate genes depends on repression of these genes in non-neuronal cells by a factor belonging to a large subfamily of zinc finger proteins that includes scrt and sna (Chong et al. 1995; Schoenherr and Anderson 1995). Thus, nervous system specific gene expression depends on two forms of negative regulation: (1) repression of non-neuronal genes in the nervous system, and (2) repression of nervous system-specific gene expression in non-neuronal tissues. This suggests that repression must be considered on par with activation as a general mechanism for achieving nervous system specific gene expression.

\section{The role of known pan-neural genes in neurogenesis}

Data described above suggest that scrt and $d p n$ collaborate to repress expression of non-neuronal genes in neuroblasts. Although DNA binding has not yet been demonstrated for Scrt, the amino acid sequence in the DNAbinding zinc finger region is highly similar to Sna, which does bind specific DNA sequences and has been shown to behave as a repressor (Ip et al. 1992). Similarly, the bHLH region of Dpn is closely related to Hairy, which binds functionally important sequences in the achaete promoter to repress gene expression (Van Doren et al. 1994; Ohsako et al. 1994). Recently, Dpn also has been found to bind DNA (K. Wallace and $\mathrm{H}$. Vaessin, in prep.). Likewise, $\mathrm{E} / \mathrm{spl} / \mathrm{m} 8$, another protein with a bHLH region related to Hairy, binds DNA and this activity is required to mediate the $E(s p l)^{D}$ phenotype (Tietze et al. 1992). Sna has been shown to function as a repressor over short distances (<100-150 bp; Ip et al. 1992; Gray et al. 1994). Dpn, Hairy, and $E(s p l)$ proteins repress transcription of target genes by recruiting Groucho through an interaction with the carboxy-terminal WRPW motif (Ohsako et al. 1994; Paroush et al. 1994; Van Doren et al. 1994), although it remains to be determined whether this takes place over short or long distances $(>1 \mathrm{~kb})$. Thus, it is possible that scrt and $d p n$ collaborate through different mechanisms to repress expression of target genes. In this case, the partial redundant function of these two genes would not be attributable to one gene substituting for the other as has been observed in the case of the structurally related genes comprising the AS-C, the E(spl) complex, and the myogenic family of bHLH-encoding genes.

Other known pan-neural genes may collaborate to establish neuronal fates by different mechanisms. For example, asense (Gonzalez et al. 1989; Brand et al. 1993; Domínguez and Campuzano 1993) is likely to function as an activator of neuronal genes, pros (Doe et al. 1991; Vaessin et al. 1991) turns off expression of pan-neural genes such as dpn in GMCs (Vaessin et al. 1991), sca (Mlodzik et al. 1990) encodes a secreted factor that inhibits neighboring non-neuronal cells from adopting neuronal fates, and cyclin $A$ (Lehner and O'Farrell 1989) most likely functions to regulate neuron-specific cell cycle progression because maternal cyclin stores have largely disappeared by the time these late embryonic cell divisions take place. Thus, neuron-specific gene expression appears to be accomplished by a combination of negative transcription factors such as Scrt and Dpn repressing non-neuronal gene expression, and positive factors such as Asense and the recently identified vertebrate bHLH protein NeuroD (Lee et al. 1995), which activate expression of neuron-specific genes. These neuron autonomous functions in combination with lateral inhibition of neighbors mediated by secreted factors such as Sca represent three of the most obvious mechanisms by which pan-neural genes might function to promote primary neuronal precursor fates. Expression of these primary precursor genes is then terminated by pros, which permits these cells to move on to the next developmental stage of neurogenesis. The diversity of pan-neural gene function and the regulation of pan-neural genes by different primary upstream regulators (Bier et al. 1992; Jarman et al. 1993; Ip et al. 1994; Vaessin et al. 1994; Emery and Bier 1995), suggests that the neuronal tissue type identity is established by distinct parallel functions rather than by a single orchestrating master gene.

\section{Neurogenesis versus myogenesis}

It is noteworthy that cells devoted to forming mesoderm and neuronal tissues express the highly related Scrt and Sna zinc finger proteins in tissue-specific patterns. A global role in establishing a common tissue identity also has been proposed for Esc, which participates in distinguishing imaginal diploid cells from other differentiated larval cells that become polyploid (Hayashi et al. 1993; Fuse et al. 1994). A collaboration between bHLH proteins and zinc finger proteins may be an important parallel between formation of the mesoderm and the nervous system. In the mesoderm, Sna directly represses the expression of nonmesodermal target genes such as rho, which participates in specification of the neuroectoderm, and the bHLH protein encoded by twist (Twi) acts as an activator of mesoderm-specific genes. In the nervous system, bHLH genes of the AS-C (including the pan-neural asense gene) are required for activation of 
neuronal genes whereas $s c r t$ and $d p n$ directly or indirectly repress expression of the epidermal Egf-r gene. Whereas single mutant phenotypes of asense, scrt, and $d p n$ are subtle, the combined action of negative and positive transcription factors during neurogenesis may be analogous to that of Sna and Twi during myogenesis. It will be interesting to determine whether a protein in the Dpn, Hairy, and E(spl) repressor subclass of WRPW bHLH proteins also contributes to myogenesis, perhaps by collaborating with Sna to repress expression of neuroectodermal genes.

\section{Materials and methods}

Fly stocks

Pan-neural insertions of the P-lacW vector into the 64A locus were generated in the course of the enhancer trap screen of Bier et al. (1989). $d p n$ mutant stocks have been described previously (Bier et al. 1992). All genetic markers and chromosome balancers used are described in Lindsley and Grell (1968) and Lindsley and Zimm (1992). Df(3L)A466 was kindly provided by Rob Jackson (Worchester Foundation, Shrewsbury, MA). Unless specifically stated, stocks were obtained from either the Bloomington Indiana or Bowling Green Ohio Stock Centers.

\section{Isolation of transposase-induced $\mathrm{scrt}^{i o}$ revertants}

Transposase-induced revertants of the single element scrt enhancer trap $\mathrm{P}-\mathrm{lacW}$ insertion were isolated by the following scheme. Flies homozygous for the viable single element P-lacW insertion into scrt locus were crossed to a stock of the genotype $y w ; \Delta 2-3 \mathrm{Sb} / \mathrm{TM} 6$. Single $\left.y w ; \mathrm{P}-\mathrm{lacW} / \mathrm{w}^{+}\right) / \Delta 2-3 \mathrm{Sb}$ male progeny from this cross were crossed to the $y w ; H^{B 55} / T M 6$ females in vials. Progeny from these crosses were screened for $w$ (non$\mathrm{Sb})$ jump-out $\left(s c r t^{j \circ}\right)$ male revertants. Single $s c r t^{i o}$ males then were crossed to $y w ; H^{B 55} / T M 6$ females fonly one male per vial was mated to assure that independent events were recovered), and balanced $\left(w^{-}\right) / y w ; s c r t^{i o} / T M 6$ stocks were established. Homozygous viable revertant chromosomes were discarded, whereas lethal or semilethal $s c r t^{i o}$ revertants were retained. DNA was prepared from escaping flies homozygous for the $s c r t^{j 06}, s c r t^{j 011}, s c r t^{i 014}, s c r t^{j o 16}$, and $s c r t^{j 017}$ semi-lethal revertant chromosomes and DNA lesions in these stocks were mapped with respect to the genomic walk and to the longest scrt cDNA clone by Southern blot analysis (see below).

\section{Antibody staining of embryos}

Antibody staining was performed according to Bier et al. (1990) and Sturtevant et al. (1993).

In situ hybridization to RNA in sections or whole-mount embryos

In situ hybridization to whole-mount embryos using antisense RNA probes was performed according to $\mathrm{O}^{\prime} \mathrm{Neill}$ and Bier (1994).

\section{Isolation of scrt genomic and cDNA clones}

DNA flanking the site of P-element insertion was cloned by plasmid rescue (Pirrotta et al. 1986) using genomic DNA isolated from flies carrying the double P-element insertion (see Fig. 2). Digoxigenin-labeled DNA probes synthesized to rescued fragments corresponding to both P-element ends were hybridized in situ to whole-mount embryos. The probe synthesized to a rescued fragment containing $8 \mathrm{~kb}$ of flanking genomic DNA $3^{\prime}$ to the P-element insertion site (relative to the direction of scrt transcription) hybridized to a pan-neural transcript, whereas the $1.8-\mathrm{kb}$ probe containing $5^{\prime}$ rescued DNA did not hybridize to any transcript. The $8-\mathrm{kb}$ rescued fragment was labeled with $\left[{ }^{32} \mathrm{P}\right]$ phosphate and used as a probe to screen a $\lambda$ phage genomic library and the Kuvar E7 cDNA library. A partial cDNA containing the 3' portion of an open reading was recovered from the Kuvar library, which in turn was used to screen the Kai Zinn embryonic library, from which two longer cDNA clones were isolated. These two cDNAs were sequenced on both strands. The longer of these two cDNAs represents an incompletely spliced RNA precursor molecule, and the other (3084 bp long) contains the full open reading frame encoding a predicted 664amino-acid Scrt protein. Overlapping genomic phage covering the scrt transcription unit were also isolated and restriction mapped. Breakpoints in various $s c r t^{i \circ}$ revertants were mapped to this walk by Southern blot analysis. Deletion of the full cDNA-coding region in $s c r t^{i o 11}, s c r t^{i 016}$, and $s c r t^{i 017}$ mutants also was confirmed by in situ hybridization with cDNA and genomic probes. In the case of $s c r t^{j o 11}$, embryos were also collected from $s c r t^{i o 11} / T M 6 /$ lacZ flies. As expected, embryos lacking the $T M 6 / / a c Z$ balancer did not label with the scrt probe.

\section{Construction of the scrt $H S$ vector}

The region of scrt cDNA clone between a BamHI site at nucleotide 530174 nucleotides upstream from the initiator ATG of the predicted Scrt protein) and the HincII sitc at nucleotide 2752 (157 nucleotides downstream of the termination codon) was subcloned into Bluescript. The Hincll site was then changed to an $X b a$ I site with linkers so that the scrt insert was flanked at both ends with $\mathrm{XbaI}$ sites (an endogenous $\mathrm{XbaI}$ site is present in the Bluescript polylinker immediately upstream of the BamHI site). The $2.2-\mathrm{kb} \mathrm{XbaI}$ fragment containing the full scrt open reading frame and minimal 5 '- and $3^{\prime}$-untranslated sequences then was inserted into the $\mathrm{P}[\mathrm{hs}-\mathrm{CaSpeR}$ ) vector (Bang and Posakony 1992). Both sense (HS-scrt) and antisense (HS-anti-scrt) orientations of the scrt insert were recovered in $\mathrm{P}[\mathrm{hs}-\mathrm{CaSpeR}]$, and these constructs were injected into fly embryos according to standard methods (Spradling 1986). Several transformant lines were isolated and tested for phenotype following heat shock. The three HS-scrt sense lines tested all generate similar adult bristle phenotypes (described in text).

\section{Other molecular techniques}

Plasmid rescue from minipreps of fly DNA was performed according to Pirrotta (1986). Other cloning techniques followed standard procedures, as in Maniatis et al. (1982).

\section{Acknowledgments}

We thank Yuh Nung Jan and Lily Jan, in whose laboratory this work was initiated, Larry Zipursky for comments on the manuscript, and Kathryn S. Burton for assembling the figures. We thank Jason W. O'Neill, Brian Biehs, Robya Tuma, and James Lowery for technical assistance. We thank Dr. Leonard Deftos for supplying the cho chordotonal organ marker and Benny Shilo for the anti-EGF-R antibody. This work was supported by National Institutes of Health grant RO1-NS29870-01, and research grant 5-FY92-1175 from the March of Dimes Birth Defects Foundation. E.B. was supported by funds from the 
McKnight Neuroscience Foundation, Sloan Foundation, and an American Cancer Society Junior Faculty Award.

The publication costs of this article were defrayed in part by payment of page charges. This article must therefore be hereby marked "advertisement" in accordance with 18 USC section 1734 solely to indicate this fact.

\section{References}

Alberga, A., J-L. Boulay, E. Kempe, C. Dennefeld, and M. Haenlin. 1991. The snail gene required for mesoderm formation in Drosophila is expressed dynamically in derivatives of all three germ layers. Development 111: 983-992.

Alonso, M.C. and C.V. Cabrera. 1988. The achaete-scute complex of Drosophila melanogaster comprises four homologous genes. EMBO J. 7: 2585-2591.

Artavanis-Tsakonas, S. and P. Simpson. 1991. Choosing a cell fate: A view from the Notch locus. Trends Genet. 7:403407.

Bang, A.G. and J.W. Posakony. 1992. The Drosophila gene Hairless encodes a novel basic protein that controls alternative cell fates in adult sensory organ development. Genes \& Dev. 6: 1752-1769.

Bier, E., H. Vaessin, S. Shepherd, K. Lee, K. McCall, S. Barbel, L. Ackerman, R. Carretto, T. Uemura, E. Grell, L.Y. Jan, and Y.N. Jan. 1989. Searching for pattern and mutation in the Drosophila genome with a P-lacZ vector. Genes \& Dev. 3: 1273-1287.

Bier, E., L.Y. Jan, and Y.N. Jan. 1990. rhomboid, a gene required for dorsoventral axis establishment and for peripheral nervous system development in Drosophila melanogaster. Genes \& Dev. 4: 190-203.

Bier, E., H. Vaessin, S. Younger-Shepherd, L.Y. Jan, and Y.N. Jan. 1992. deadpan, an essential pan-neural gene in Drosophila, encodes a helix-loop-helix protein similar to the hairy gene product. Genes \& Dev. 6: 2137-2151.

Bodmer, R. and Y.N. Jan. 1987. Morphological differentiation of the embryonic peripheral neurons in Drosophila. Wilhelm Roux's Arch. Dev. Biol. 196: 69-77.

Boulay, J.L., C. Dennefeld, and A. Alberga. 1987. The Drosophila developmental gene snail encodes a protein with nucleic acid binding fingers. Nature 330: 395-398.

Brand, M., A.P. Jarman, L.Y. Jan, and Y.N. Jan. 1993. The regulation and function of the helix-loop-helix gene, asense, in Drosophila precursors. Development 119: 1-17.

Brown, N.L., C.A. Sattler, S.W. Paddock, and S.B. Carroll. 1995. Hairy and Emc negatively regulate morphogenetic furrow progression in the Drosophila eye. Cell 80: 879-887.

Campos-Ortega, J.A. 1994. Genetic mechanisms of early neurogenesis in Drosophila melanogaster. J. de Physiol. 88: 111122.

Campos-Ortega, J.A. and V. Hartenstein. 1985. The embryonic development of Drosophila melanogaster. Springer-Verlag, New York.

Chong, J.A., J. Tapia-Ramirez, S. Kim, J.J. Toledo-Aral, Y. Zheng, M.C. Boutros, Y.M. Altshuller, M.A. Frohman, S.D. Kraner, and G. Mandel. 1995. REST: A mammalian silencer protein that restricts sodium channel gene expression to neurons. Cell 80: 949-957.

Doe, C.Q., Q. Chu-LaGraff, D.M. Wright, and M.P. Scott. 1991. The prospero gene specifies cell fates in the Drosophila central nervous system. Cell 65: 451-464.

Domínguez, M. and S. Campuzano. 1993. asense, a member of the Drosophila achaete-scute complex, is a proneural and neural differentiation gene. $E M B O$ J. 12: 2049-2060.
Emery, J. and E. Bier. 1995. Specificity of PNS and CNS regulatory sub-elements comprising the pan-neural enhancers of deadpan and scratch genes is achieved by repression. Development (in press).

François, V., M. Solloway, J.W. O'Neill, J. Emery, and E. Bier. 1994. Dorsal-ventral patterning of the Drosophila embryo depends on a putative negative growth factor encoded by the short gastrulation gene. Genes \& Dev. 8: 2602-2616.

Fuse N., S. Hirose, and S. Hayashi. 1994. Diploidy of Drosophila imaginal cells is maintained by a transcriptional repressor encoded by escargot. Genes \& Dev. 8: 2270-2281.

Ghysen, A., C. Dambly-Chaudiere, E. Aceves, L.Y. Jan, and Y.N. Jan. 1986. Sensory neurons and peripheral pathways in Drosophila embryos. Wilhelm Roux's Arch. Dev. Biol. 195: 281-289.

Ghysen, A., C. Dambly-Chaudiere, L.Y. Jan, and Y.N. Jan. 1993. Cell interactions and gene interactions in peripheral neurogenesis. Genes \& Dev. 7: 723-733.

Gonzalez, F., S. Romani, C. Cubas, J. Modolell, and S. Campuzano. 1989. Molecular analysis of the asense gene, a member of the achaete-scute complex of Drosophila melanogaster, and its novel role in optic lobe development. EMBO J. 8: 3553-3562.

Gray S., P. Szymanski, and M. Levine. 1994. Short-range repression permits multiple enhancers to function autonomously within a complex promoter. Genes \& Dev. 8: 7829-7838.

Hammerschmidt, M. and C. Nüsslein-Volhard. 1993. The ex pression of a zebrafish gene homologous to Drosophila snail suggests a conserved function in invertebrate and vertebrate gastrulation. Development 119: 1107-1118.

Hartenstein, V. 1988. Development of Drosophila larval sensory organs: Spatiotemporal pattern of sensory neurons, peripheral axonal pathways and sensilla differentiation. Development 102: 869-886.

Hayashi, S., S. Hirose, T. Metcalfe, and A.D. Shirras. 1993. Control of imaginal cell development by the escargot gene of Drosophila. Development 118: 105-115.

Heberlein, U., T. Wolff, and G.M. Rubin. 1993. The TGF- $\beta$ homolog $d p p$ and the segment polarity gene hedgehog are required for propagation of the morphogenetic wave in the Drosophila retina. Cell 75: 913-926.

Ip, Y.T., R.E., Park, D. Kosman, E. Bier, and M. Levine. 1992. The dorsal gradient morphogen regulates stripes of rhomboid expression in the presumptive neuroectoderm of the Drosophila embryo. Genes \& Dev. 6: 1728-1739.

Ip, Y.T., M. Levine, and E. Bier. 1994. Neurogenic expression of snail is controlled by separable CNS and PNS promoter elements. Development 120: 199-207.

Jan, Y.N. and L.Y Jan. 1993. HLH proteins, fly neurogenesis, and vertebrate myogenesis. Cell 75: 827-830.

1994. Neuronal cell fate specification in Drosophila. Curr. Opin. Neurobiol. 4: 8-13.

Jarman, A.P., M. Brand, L.Y. Jan, and Y.N. Jan. 1993. The regulation and function of the helix-loop-helix gene, asense in Drosophila neural precursors. Development 119: 19-29.

Kammermeyer, K.L. and S.C. Wadsworth. 1987. Expression of Drosophila epidermal growth factor homologue in mitotic cell populations. Development 100: 201-210.

Katzen, A.L., T. Kornberg, and J.M. Bishop. 1991. Expression during Drosophila development of DER, a gene related to erbB-l and neu: Correlations with mutant phenotypes. Dev. Biol. 145: 287-301.

Kosman, D., Y.T. Ip, M. Levine, and K. Arora 1991. Establishment of the mesoderm neuroectoderm boundary in the Drosophila embryo. Science 254: 118-122.

Lee, J.E., S.M. Hollenberg, L. Snider, D.L. Turner, N. Lipnick, 
and H. Weintraub. 1995. Conversion of Xenopus ectoderm into neurons by NeuroD, a basic helix-loop-helix protein. Science 268: 836-844.

Lehner, C. and P. O'Farrell. 1989. Expression and function of Drosophila cyclin A during embryonic cell cycle progression. Cell 56: 957-968.

Leptin, M. 1991. twist and snail as positive and negative regulators during Drosophila mesoderm development. Genes \& Dev. 5: 1568-1576.

Lindsley, D.L. and E.H. Grell. 1968. Genetic variations in Drosophila melanogaster. Carnegie Institute of Washington, Washington, D.C.

Lindsley, D.L. and G.G. Zimm. 1992. The genome of Drosophila melanogaster. Academic Press, San Diego, CA.

Ma, C.Y., P.A. Beachy, and K. Moses. 1993. The segment polarity gene hedgehog is required for progression of the morphogenetic furrow in the developing Drosophila eye. Cell 75: 927-938.

Maniatis, T., E.F. Fritsch, and J. Sambrook. 1982. Molecular cloning: A laboratory manual. Cold Spring Harbor Laboratory, Cold Spring Harbor, New York.

Mlodzik, M., N.E. Baker, and G.M. Rubin. 1990. Isolation and expression of scabrous, a gene regulating neurogenesis in Drosophila. Genes \& Dev. 4: 1848-1861.

Nieto, M.A., M.F. Bennett, M.G. Sargent, and D.G. Wilkinson. 1992. Cloning and developmental expression of Sna, a murine homologue of the Drosophila snail gene. Development 116: 227-237

Nieto, M.A., M.G. Sargent, D.G. Wilkinson, and J. Cooke. 1994. Control of cell behavior during vertebrate development by Slug, a zinc finger gene. Science 264: 835-839.

Ohsako, S., J. Hyer, G. Panganiban, I. Oliver, and M. Caudy. 1994. Hairy functions as a DNA-binding helix-loop-helix repressor of Drosophila sensory organ formation. Genes \& Dev. 8: 2729-2742.

O'Neill, J.W. and E. Bier. 1994. Double-label in situ hybridization using biotin and dioxigenin-tagged RNA probes. BioTechniques 17: 870-875.

Paroush, Z., R.F. Finley, T. Kid, S.M. Wainright, P.W. Ingham, R. Brent, and D. Ish-Horowicz. 1994. Groucho is required for Drosophila neurogenesis, segmentation, and sex determination and interacts directly with Hairy-related bHLH proteins. Cell 79: 805-815.

Pirrotta, V. 1986. Cloning Drosophila genes. In Drosophila: A practical approach (ed. D.R. Roberts), pp. 83-110. IRL Press, Washington, D.C.

Rao, Y., H. Vaessin, L.Y. Jan, and Y.N. Jan. 1991. Neuroectoderm in Drosophila embryos is dependent on the mesoderm for positioning but not for formation. Genes \& Dev. 5: 1577 1588.

Romani, S., S. Campuzano, and J. Modolell. 1987. The achaetescute complex is expressed in neurogenic regions of Drosophila embryos. EMBO I. 6: 2085-2092.

Romani, S., S. Campuzano, E.R. Macagno, and J. Modolell. 1989. Expression of achaete and scute genes in Drosophila imaginal discs and their function in sensory organ development. Genes \& Dev. 3: 997-1007.

Sargent, M.G. and M.F. Bennett. 1990. Identification in Xenopus of a structural homologue of the Drosophila gene snail. Development 109: 967-973.

Schoenherr, C.J. and D.J. Anderson. 1995. The neuron-restrictive silencer factor (NRSF): A coordinate repressor of multiple neuron-specific genes. Science 267: 1360-1363.

Smith, D.E., F. Franco del Amo, and T. Gridley. 1992. Isolation of Sna, a mouse gene homologous to the Drosophila genes snail and escargot: Its expression pattern suggests multiple roles during postimplantation development. Development 116: 1033-1039.

Spradling, A. 1986. P-element-mediated transformation. In Drosophila: A practical approach (ed. D.B. Roberts), pp. 175-197. IRL Press, Washington, D.C.

Sturtevant, M.A., M. Roark, and E. Rier. 1993. The Drosophila rhomboid gene mediates the localized formation of wing veins and interacts genetically with components of the EGF-R signaling pathway. Genes \& Dev. 7: 961-973.

Sturtevant, M., J.W. O'Neill, and E. Bier. 1994. Down-regulation of Drosophila Egf- $r$ mRNA levels following hyperactivated receptor signaling. Development 120: 2593-2600.

Thisse, B., C. Stoetzel, C. Gorostiza-Thisse, and F. PerrinSchmitt. 1988. Sequence of the twist gene and nuclear localization of its protein in endomesodermal cells of early Drosophila embryos. EMBO I. 7: 2175.

Thisse, C., B. Thisse, T.F. Schilling, and J.H. Postlethwait. 1993. Structure of the zebrafish snaill gene and its expression in wild-type, spadetail and no tail mutant embryos. Development 119: 1203-1215.

Tietze, K., N. Oellers, and E. Knust. 1992. Enhancer of split ${ }^{\mathrm{D}}$, a dominant mutation in Drosophila and its use in the study of functional domains of a helix-loop-helix protein. Proc. Natl. Acad. Sci. 89: 6152-6156.

Vaessin, H., E. Grell, E. Wolff, E. Bier, L. Jan, and Y.N Jan. 1991 prospero is expressed in neuronal precursors and encodes a nuclear protein that is involved in the control of axonal outgrowth in Drosophila. Cell 67: 941-953.

Vaessin, H., M. Brand, L.Y. Jan, and Y.N. Jan. 1994. daughterless is essential for neuronal precursor differentiation but not for initiation of neuronal precursor formation in the Drosophila embryo. Development 120: 935-945.

Van Doren, M., A.M. Bailey, J. Esnayra, K. Ede, and J. Posakony. 1994. Negative regulation of proneural gene activity: Hairy is a direct transcriptional repressor of achaete. Genes \& Dev. 8: $2729-2742$.

Villares, R. and C.V. Cabrera. 1987. The achaete-scute gene complex of $\mathrm{D}$. melanogaster: Conserved domains in a subset of genes required for neurogenesis and their homology to myc. Cell 50: 415-424.

Whitely, M., P.D. Noguchi, S.M. Sensabaugh, W.F. Odenwald, and I.A. Kassis. 1992. The Drosophila gene escargot encodes a zinc-finger motif found in snail-related genes. Mech. Dev. 36: $117-127$

Zak, N.B. and B.Z. Shilo. 1992. Localization of DER and the pattern of cell divisions in wild-type and Ellipse eye imaginal discs. Dev. Biol. 149: 448-456.

Zak, N.B., R.J. Wides, E.D. Schejter, E. Raz, and B.Z. Shilo. 1990. Localization of the DER/flb protein in embryos: Implications on the faint little ball lethal phenotype. Development 109: 865-874. 


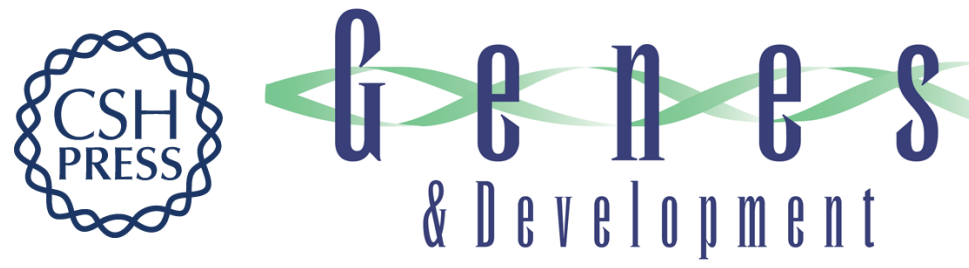

\section{scratch, a pan-neural gene encoding a zinc finger protein related to snail, promotes neuronal development.}

M Roark, M A Sturtevant, J Emery, et al.

Genes Dev. 1995, 9:

Access the most recent version at doi:10.1101/gad.9.19.2384

References This article cites 61 articles, 35 of which can be accessed free at:

http://genesdev.cshlp.org/content/9/19/2384.full.html\#ref-list-1

License

Email Alerting

Service

Receive free email alerts when new articles cite this article - sign up in the box at the top right corner of the article or click here.

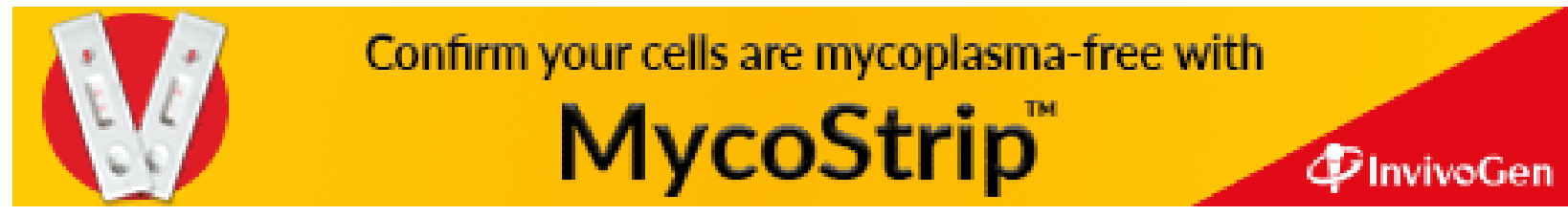

